\title{
In Polish medicine
}

\author{
Marian Zembala
}

Kardiochirurgia i Torakochirurgia Polska 2013; 3: 299

In Polish medicine, the National Registry of Cardiac Surgery (KROK), is - beside three national cardiology registries - the reason for pride and satisfaction not only for Polish cardiac surgeons, but also the healthcare payers: the Ministry of Health and the National Health Fund. The Registry enables objective evaluation of the results of clinical services from medical, economical and organizational a perspective. Today it would be difficult to imagine a situation where a payer does not know the final results of the services he is paying for, or where a health care provider experiences unpredictable consequences of the performed services unpaid due to lack of means.

Analysis of the National Registry of Cardiac Surgery 2012 indicates a significant increase in the number of cardiac surgery procedures performed per annum, as compared to 2011. This applies to coronary procedures - increase of 446 , valve - increase of 302, aortic aneurysms - increase of 132 , which is a good evidence of proper implementation of the ESC/ EACTS Guidelines in practice and importance of the Heart Team in Polish cardiovascular medicine. Significant increase in number of operations is accompanied by the improvement of surgical treatment outcomes, evaluated in early in-hospital period. In addition, noticeable development of minimally invasive techniques and procedures in Polish cardiac surgery, as well as the improvement of their accessibility for Polish patients is worth emphasizing.

Despite having still limited budget and being dependant on two healthcare payers - the Ministry of Health and the National Health Fund, in Poland, against the background of other developed European countries we observe high quality of cardiac surgery treatment. Access to KROK Registry data, provided exclusively for caregivers and supervising units, enables systematic monitoring of the quality and accessibility of the cardiac surgery services in particular cities, voivodeships and regions of Poland.

We observe a significant decrease in number of patients qualified for costly treatment abroad (for public money), which proves the increased accessibility of Polish patients to all cardiac surgery and transplant procedures in our country also as a result of the efforts of the leaders of Polish cardiac surgery to make it possible.

Regardless of the mentioned above positive actions and good, documented treatment outcomes in Polish cardiac surgery, the above presented numbers indicate growing number of cardiac surgery procedures in more and more difficult, older population. This requires increased funds for cardiac surgery treatment in Poland and creation of the new task groups (DRG), which would reflect a real scale of efforts of the medical teams and factual costs of treatment.

Prof. Marian Zembala, MD PhD FESC National consultant in cardiac surgery 